\title{
Komunikasi Interpersonal dan Kinerja Usaha Kecil Menengah di Palangka Raya; Berbagi Pengetahuan sebagai Mediasi
}

\author{
Christine Natalia Hutapea \\ Jurusan Manajemen
}

Universitas Palangka Raya, Indonesia

e-mail: Christinenataliahutapea79@Gmail.com

\begin{abstract}
Abstrak
Tujuan, - Penelitian ini bertujuan untuk memberikan penjelasan secara empiris tentang Pengaruh komunikasi interpesonal terhadap kinerja UMKM dengan knowledge sharing sebagai intervening. Desain/Methodologi/Pendekatan - Metode penelitian yang digunakan deskriptif-kuantitatif. Unit analisa penelitian ini adalah Pegawai yang berjumlah 139 orang dengan teknik sampel sensus atau sampling total. Data yang terkumpul dianalisis dengan menggunakan pendekatan Structural Equation Modelling (SEM). Software yang digunakan adalah SmartPLS 3.2.8,

Temuan penelitian - Hasil penelitian menunjukkan bahwa Pengaruh komunikasi interpesonal berpengaruh positif dan signifikan terhadap kinerja umkm, Pengaruh komunikasi interpesonal berpengaruh positif dan signifikan terhadap knowledge sharing, knowledge sharing berpengaruh positif dan signifikan terhadap kinerja umkm, knowledge sharing meintervening pengaruh komunikasi interpesonal terhadap kinerja umkm..
\end{abstract}

Kata kunci: Pengaruh komunikasi interpesonal, Kinerja Umkm , Knowledge Sharing

\section{Interpersonal Communication and Performance of Small and Medium Enterprises in Palangka Raya; Knowledge Sharing as Mediation}

\begin{abstract}
Purpose, - This research aims to provide empirical explanation on the influence of interpesonal communication on UMKM performance with knowledge sharing as intervening.

Design/methodology/approach - The research method used is descriptive-quantitative. This research analysis Unit is a staff of 139 people with census sample techniques or total sampling. The collected Data is analyzed using a Structural Equation Modelling (SEM) approach. The Software used is SmartPLS 3.2.8.

Findings - The results showed that the influence of interpesonal communication has positive and significant impact on umkm performance, the influence of interpesonal communication is positive and significant impact on knowledge sharing, influential knowledge sharing Positive and significant to umkm performance, knowledge sharing intervening the influence of interpesonal communication towards umkm performance
\end{abstract}

Keywords: The influence of interpesonal communication, Umkm performance, Knowledge Sharing

Jurnal Manajemen Sains dan Organisasi

Vol 1, No 3, 2020 pp. $161-170$ FEB UPR Publishing $2685-4724$
Christine Natalia Hutapea. Published in the Jurnal Manajemen sains dan Organsasi. Published by FEB UPR Publishing Limited. This article is published under the Creative Commons Attribution (CC BY 4.0) licence. Anyone may reproduce, distribute, translate and create derivative works of this article (for both commercial and non-commercial purposes), subject to full attribution to the original publication and authors. 


\section{PENDAHULUAN}

Usaha Mikro Kecil Menengah (UMKM) memainkan peran penting dalam mendukung pertumbuhan perekonomian di Indonesia. Dengan adanya sektor UMKM, pengangguran akibat angkatan kerja yang tidak terserap dalam dunia kerja menjadi berkurang. Sektor UMKM juga telah terbukti menjadi pilar perekonomian yang tangguh di Indonesia. Bahkan dalam terjadinya krisis ekonomi banyak usaha berskala besar yang mengalami stagnan, akan tetapi sektor UMKM terbukti tangguh dan memiliki daya tahan yang relatif kuat dalam menghadapi krisis tersebut.

UMKM di Kota Palangka Raya, Provinsi Kalimantan Tengah terus mendorong pelaku usaha mikro, kecil, dan menengah (UMKM) di kota setempat dapat menghasilkan produk atau jasa yang menjadi salah satu daya tarik wisatawan. Di antaranya UMKM jasa kuliner ini didorong menjadi daya tarik wisata di kota kita ialah dengan membangun pusat kuliner di Jalan Yos Sudarso. produk kuliner yang memiliki kekhasan merupakan salah satu yang paling dicari oleh orang yang berkunjung di suatu derah sehingga pihaknya juga terus mendorong keberadaan pelaku usaha kuliner di kota setempat dapat menyajikan makanan yang memiliki kekhasan tersendiri dibanding daerah lain. Mengajak para pelaku UMKM kuliner ini terus berkreasi dan berinovasi, namun tetap menyajikan kekhasan daerah.

Keberadaan makanan khas daerah yang dipadu dengan tata letak dan penataan menarik akan membuat pengunjung penasaran dan semakin betah. Kawasan pusat wisata kuliner yang terletak di Jalan Yos Sudarso Palangka Raya saat ini dalam tahap pembangunan. Dari sekitar rencana sebanyak 52 kontainer yang disiapkan untuk menaruh perlengkapan berdagang, saat ini baru tersedia 27 unit kontainer. Tahap pembangunannya pun memasuki penyiapan taman, lokasi parkir, dan dan penyiapan jalur pejalan kaki serta pengecatan kontainer dengan ciri khas ukiran suku dayak termasuk persiapan pemasangan lampu penerangan. Apabila kita mencermati pertumbuhan bisnis rumah makan baik di kota Palangkaraya, sungguh sangat signifikan kenaikan jumlahnya, begitu banyak orang membuka investasi rumah makan. Berbagai variasi menu dan jenis etnik yang ditawarkan, aneka ragam interior design yang ditampilkan, hal ini yang sangat membanggakan perkembangan bisnis ini. Disisi lain masih sangat banyak para pengelola rumah yang mengabaikan aspek penting dalam bisnis ini yaitu Kualitas Sumber Daya Manusia (SDM) dalam memberikan pelayanan yang terbaik, baik di bagian pelayanan (service) maupun dibagian pengolahan masih banyak dari mereka yang tidak mendalami akan penting menjaga kualitas makanan/minuman dan pelayanan di rumah makan yang dikelolanya demi memuaskan konsumennya.

Komunikasi merupakan aktivitas dasar manusia. Dengan berkomunikasi, manusia dapat saling berhubungan satu sama lain baik dalam kehidupan sehari-hari di rumah tangga, di tempat pekerjaan, di pasar, dalam masyarakat atau dimana saja manusia berada. Tidak ada manusia yang tidak akan terlibat dalam komunikasi (Muhammad, 2011). Dalam upaya membangun usaha kecil menengah yang kuat perlu adanya komunikasi bisnis yang lebih baik, pendekatan pembelajaran kewirausahaan yang lebih baik yang mampu berdampak pada kinerja dan sikap pemilik usaha kecil menengah, terlebih ke negara berkembang seperti Indonesia (Soegoto, 2018).

Kemampuan komunikasi antar pimpinan dan karyawan harus terus-menerus ditingkatkan untuk menciptakan berbagi pengetahuan yang efektif. Semakin baik kemampuan seseorang dalam berkomunikasi, semakin tinggi pula peluang pesan dapat tersampaikan dengan baik. proses komunikasi dan berbagi pengetahuan mungkin variabel yang menarik dalam kaitannya dengan gaya komunikasi, karena proses pertukaran mengasumsikan. Bahkan ketika orang telah siap akses ke internet atau intranet perusahaan, orang lebih mungkin untuk berpaling kepada orang lain untuk informasi daripada sumber impersonal (Levin dan Cross 
2004). Curado, dan Vieira, (2019) menjelaskan bahwa pentingnya untuk mendorong Knowledge Sharing (KS) dilingkungan UKM. Manajer sumber daya manusia bisa mendapatkan keuntungan dari mendorong KS di antara karyawan.

Knowlegde sharing menciptakan peluang untuk memaksimalkan kemampuan organisasi untuk memenuhi kebutuhan tersebut dan menghasilkan solusi dan efisiensi yang menyediakan bisnis dengan keunggulan kompetitif. (Reid,2003). Knowlegde sharing dapat mendefinisikan sebagai budaya interaksi sosial, melibatkan pertukaran pengetahuan karyawan, pengalaman, dan keterampilan melalui seluruh Departemen atau organisasi Knowlegde sharing terdiri dari satu set pemahaman bersama yang berkaitan dengan memberikan karyawan akses ke informasi yang relevan dan membangun dan menggunakan jaringan pengetahuan dalam organisasi (Hogelet Al., 2003).

Kerangka konsep penelitian merupakan suatu bentuk kerangka berpikir yang dapat digunakan sebagai pendekatan dalam memecahkan masalah. Biasanya kerangka penelitian ini menggunakan pendekatan ilmiah dan memperlihatkan hubungan antar variabel dalam proses analisisnya. Adapun gambar kerangka konsep penelitian. dalam penelitian ini dapat dilihat pada Gambar 1.

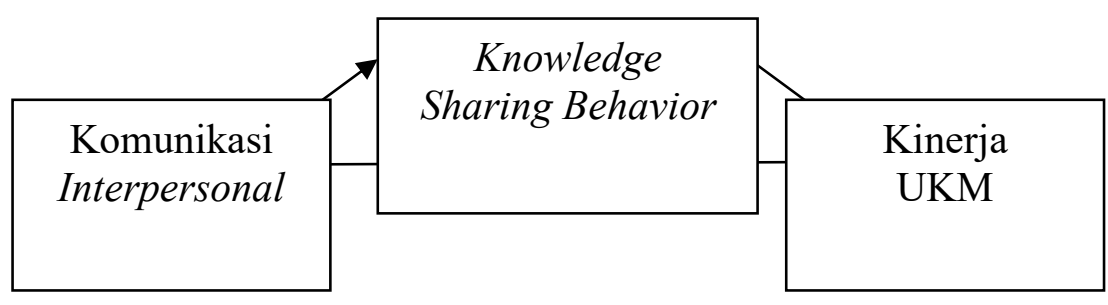

Gambar 1 Kerangka Konsep Penelitian

Diduga Komunikasi Interpersonal berpengaruh signifikan terhadap kinerja UMKM di Kota Palangka Raya? Diduga Komunikasi Interpersonal berpengaruh signifikan terhadap knowledge sharing di kota Palangka Raya? Diduga Knowledge Sharing berpengaruh signifikan terhadap Kinerja UMKM di kota Palangka Raya? Diduga ada Pengaruh Komunikasi Interpersonal Terhadap kinerja UMKM melalui Knowledge Sharing sebagai Intervening?

\section{METODE PENELITIAN}

Ruang lingkup penelitian ini adalah metode penelitian kuantitatif dapat diartikan sebagai metode penelitian yang berlandaskan pada filsafat positivisme, digunakan untuk meneliti pada populasi atau sampel tertentu, teknik pengambilan sampel pada umumnya dilakukan secara random, pengumpulan data menggunakan instrumen penelitian, analisis data bersifat kuantitatif statistik dengan tujuan untuk menguji hipotesis yang telah ditetapkan. 
Tabel 1 Definisi Operasional Variabel

\begin{tabular}{|c|c|c|c|}
\hline Variabel & Definisi & Indikator & Item \\
\hline Komunikasi & Komunikasi & 1. Keterbukaan (opennes) & Nomor 1 (KI_1) \\
\hline Interpersonal & merupakan aktivitas & 2. Empati (empathy) & Nomor 2 (KI_2) \\
\hline & dasar manusia. & 3. dukungan (support) & Nomor 3 (KI_3) \\
\hline Menurut & Dengan & 4. Rasa positif & Nomor 4 (KI_4) \\
\hline $\begin{array}{l}\text { Muhammad } \\
(2011)\end{array}$ & $\begin{array}{l}\text { berkomunikasi, } \\
\text { manusia dapat saling } \\
\text { berhubungan satu } \\
\text { sama lain }\end{array}$ & $\begin{array}{ll} & \text { (positiveness) } \\
\text { 5. } & \text { Kesamaan (equality) }\end{array}$ & Nomor 5 (KI_5) \\
\hline $\begin{array}{l}\text { Knowledge } \\
\text { Sharing }\end{array}$ & $\begin{array}{l}\text { Mentransferkan } \\
\text { pengetahuan dan }\end{array}$ & $\begin{array}{l}\text { 1. Fasilitas untuk } \\
\text { saling berdiskusi }\end{array}$ & $\begin{array}{l}\text { Nomor } 6\left(\mathrm{KS} \_1\right) \\
\text { Nomor } 7 \text { (KS_2) }\end{array}$ \\
\hline $\begin{array}{l}\text { Behavior } \\
\text { Menurut }\end{array}$ & $\begin{array}{lr}\text { untuk } & \text { mendorong } \\
\text { karyawan } & \text { dalam } \\
\text { menggunakan } & \text { sistem }\end{array}$ & $\begin{array}{l}\text { 2. fasilitas untuk } \\
\text { mendokumentasikan } \\
\text { permasalahan dan solusi }\end{array}$ & Nomor 8 (KS_3) \\
\hline Ismail (2012) & knowledge sharing. & $\begin{array}{l}\text { 3. Fasilitas untuk } \\
\text { mendistribusikan } \\
\text { informasi terbaru }\end{array}$ & \\
\hline Kinerja & Kinerja merupakan & 1. Pertumbuhan penjualan & Nomor 9 (KU_1) \\
\hline UMKM & ukuran keberhasilan & 2. Pertumbuhan modal & Nomor10 (KU_2) \\
\hline & sebuah identitas usaha & 3. Penambahan tenaga & Nomor11 (KU_3) \\
\hline Menurut & dalam mencapai & kerja setiap tahun & Nomor12 (KU_4) \\
\hline Munizu, 2010) & tujuannya & $\begin{array}{l}\text { 4. Pertumbuhan pasar dan } \\
\text { pemasaran } \\
\text { 5. Pertumbuhan } \\
\text { keuntungan / laba usah }\end{array}$ & Nomor13 (KU_5) \\
\hline
\end{tabular}

\section{HASIL DAN PEMBAHASAN}

Setelah Pengumpulan data dilakukan dengan menyebar kuesioner yang dibagikan secara langsung kepada responden yaitu para pengusaha rumah makan dan cafe dijalan Yos di jalan galaxi, Rumah Makan dijalan Sisingamangaraja, Rumah makan di jalan kini balu 21 kuesioner. Dari jumlah data tersebut sebanyak 155 kuesioner yang kembali. data yang tidak kembali Sebanyak 16 kuesioner, dan data kuesioner yang rusak sebanyak 16 kuesioner. Dengan demikian maka data yang diperoleh sebanyak 139 kuesioner saja yang dapat digunakan untuk membuktikan hipotesis penelitian.

Tabel 3 Karakteristik Responden Berdasarkan Jenis Kelamin

\begin{tabular}{lcr}
\hline Jenis Kelamin & Jumlah (orang) & Persentase (\%) \\
\hline Laki-laki & 80 & $57,55 \%$ \\
Perempuan & 59 & $42,45 \%$ \\
Total & 139 & $100,00 \%$ \\
\hline
\end{tabular}

Sumber Hasil pengolahan data Primer (2019

Berdasarkan Tabel 3 karakteristik responden berdasarkan jenis kelamin, dapat dilihat bahwa Pusat kuliner Tunggal Sangomang di Palangka Raya membuktikan 80 orang dari 139 responden berjenis kelamin laki-laki dengan persentase $57,55 \%$. Sedangkan sisanya yaitu 59 orang dari 139 responden yang berjenis kelamin perempuan dengan persentase $42,45 \%$ Dilihat dari jenis kelamin responden pada penelitian ini didominasi oleh laki-laki yang 
berjumlah 80 orang atau $57,55 \%$ lebih banyak dari jumlah perempuan yang hanya berjumlah 59 orang atau $42,45 \%$.

Tabel 4 Karakteristik responden berdasarkan Usia

\begin{tabular}{lcc}
\hline Usia & Jumlah (orang) & Persentase(\%) \\
\hline $17-23$ tahun & 25 & $17,98 \%$ \\
$24-30$ tahun & 35 & $25,18 \%$ \\
$31-40$ tahun & 50 & $35,98 \%$ \\
$41-55$ tahun & 29 & $20,86 \%$ \\
Total & 139 & $100 \%$
\end{tabular}

Sumber Hasil pengolahan data Primer (2019

Berdasarkan Tabel 4 karakteristik responden berdasarkan Usia, dapat dilihat bahwa Pusat kuliner Tunggal Sangomang di Palangka Raya membuktikan 25 orang dari 139 responden memiliki usia sekitar 17 -23 tahun dengan persentase $17,98 \%, 35$ orang dari 139 responden memiliki usia sekitar 24-30 tahun dengan persentase $25,18 \%, 50$ orang dari 139 responden memiliki usia sekitar 31-40 tahun dengan persentase 35,98\%, 29 orang dari 139 responden memiliki usia sekitar 41-55 tahun dengan persentase 20,86\%. Hasil tersebut menunjukkan bahwa usia sekitar 31-40 lebih banyak.

Tabel 5 Karakteristik Responden Berdasarkan Tingkat Pendidikan

\begin{tabular}{lcc}
\hline Pendidikan Terakhir & Jumlah (orang) & Persentase \\
\hline SMA & 110 & $79,13 \%$ \\
D1 & 4 & $2,88 \%$ \\
S1 & 25 & $17,99 \%$ \\
Total & 139 & $100 \%$ \\
\hline
\end{tabular}

Sumber Hasil pengolahan data Primer (2019)

Berdasarkan Tabel 5 karakteristik responden berdasarkan pendidikan terakhir, dapat dilihat bahwa Pusat kuliner Tunggal Sangomang di Palangka Raya membuktikan 110 orang dari 139 responden memiliki tingkat Tingkat pendidikan SMA dengan persentase 79,13\%, 4 orang dari 139 responden memiliki Tingkat pendidikan D1 dengan persentase 2,88\%, 25 orang dari 139 responden memiliki Tingkat pendidikan S1 dengan persentase 17,99\%. Hasil tersebut menunjukkan bahwa Pusat kuliner Tunggal Sangomang di Palangka Raya memiliki tingkat pendidikan SMA lebih banyak.

\section{Evaluasi measurement model (outer model)}

Pengujian validitas dan reliabilitas yang dinilai dari outer loading, AVE (Average Variance Extracted), cross loadings, cronbach's aplha dan composite reliability

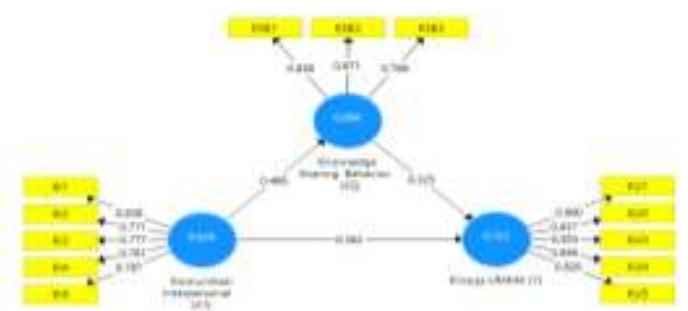

Sedangkan untuk rangkuman hasil uji validitas dan hasil uji reliabilitas dapat dilihat pada Tabel sebagai berikut: 
Tabel 6 Outer Loadings

\begin{tabular}{lll}
\hline Variabel & Indikator & Outer Loadings \\
\hline Komunikasi Interpersonal & K1 & 0,838 \\
(X1) & K2 & 0,771 \\
& K3 & 0,777 \\
& K4 & 0,781 \\
Knowledge Sharing & K5 & 0,787 \\
Behavior (X2) & KSB1 & 0,858 \\
Kinerja UMKM (Y) & KSB2 & 0,871 \\
& KU1 & 0,766 \\
& KU2 & 0,880 \\
& KU3 & 0,857 \\
& KU4 & 0,843 \\
& KU5 & 0,820
\end{tabular}

Sumber: Output SmartPLS 3.2.8 data primer diolah 2019

Berdasarkan tabel 6 diatas, diketahui bahwa masing-masing indikator variabel penelitian memiliki nilai outer loadings yang beragam. Menurut Ghozali (2014). Nilai outer loadings 0,50 sampai 0,60 dianggap cukup untuk memenuhi syarat convergent validity. Data diatas menunjukkan bahwa semua indikator memiliki nilai outer loadings $\geq 0,50$ sehingga indikator dinyatakan layak atau valid digunakan dalam penelitian dan dapat digunakan untuk analisa selanjutnya.

Selain mengamati outer loadings,convergent validity juga dapat diketahui melalui nilai AVE (Average Variant Extracted) untuk masing-masing indikator diisyaratkan nilainya harus $\geq 0,50$ untuk model yang baik.

Tabel 7. AVE (Average Variant Extracted)

\begin{tabular}{ll}
\hline Variabel & AVE (Average Variant Extracted) \\
\hline Komunikasi Interpersonal & 0,626 \\
Knowledge Sharing Behavior & 0,694 \\
Kinerja UMKM & 0,725 \\
\hline
\end{tabular}

Sumber: Output SmartPLS 3.2.8 data primer diolah 2019

Berdasarkan data dalam tabel 7 diatas, diketahui nilai AVE (Average Variant Extracted) Komunikasi Interpersonal,Knowledge Sharing Behavior dan Kinerja $\geq 0,50$. Dengan demikian dapat dinyatakan bahwa indikator variabel penelitian layak atau valid.

Tabel 8 Cross Loadings

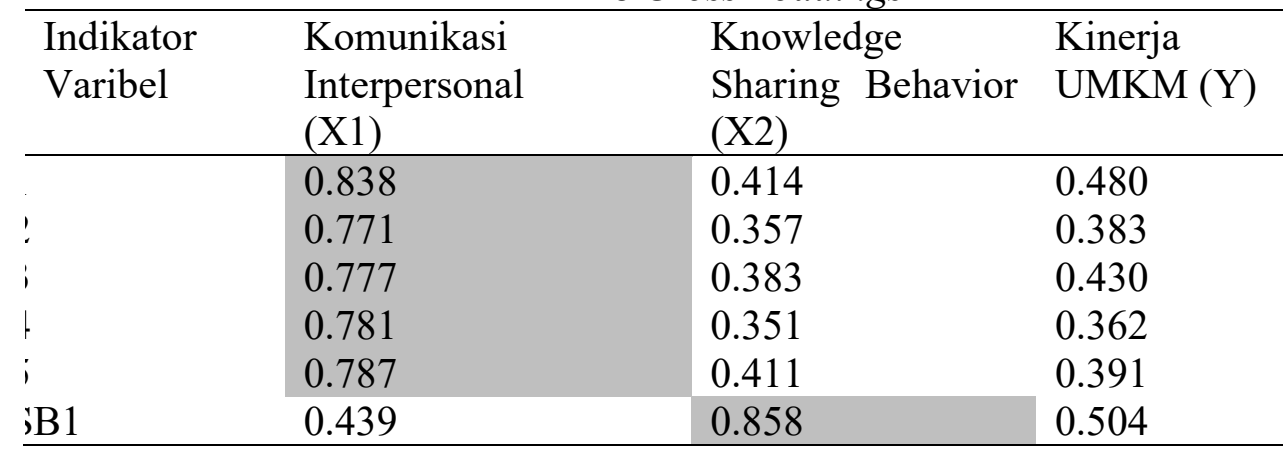




\begin{tabular}{|c|c|c|c|}
\hline B2 & 0.342 & 0.871 & 0.392 \\
\hline ;B3 & 0.424 & 0.766 & 0.335 \\
\hline J1 & 0.447 & 0.400 & 0.880 \\
\hline $\mathrm{J} 2$ & 0.401 & 0.405 & 0.857 \\
\hline J3 & 0.498 & 0.394 & 0.853 \\
\hline J4 & 0.519 & 0.426 & 0.846 \\
\hline & 0.334 & 0.510 & 0.820 \\
\hline
\end{tabular}

Sumber: Output SmartPLS 3.2.8 data primer diolah 2019

Berdasarkan data pada tabel 8 diatas, dapat diketahui bahwa masing-masing indikator pada variabel penelitian memiliki nilai Cross Loadings terbesar pada variabel dibentuknya dibandingkan dengan nilai Cross Loadings lainnya. Berdasarkan hasil yang diperoleh tersebut, dapat dinyatakan bahwa indikator yang digunakan dalam penelitian ini telah memiliki Discriminant Validity yang baik dalam menyusun variabel masing-masing.

Tabel 9 Cronbach's Alpha

\begin{tabular}{lc}
\hline Variabel & Cronbach's Alpha \\
\hline Komunikasi Interpersonal & 0,851 \\
Knowledge Sharing Behavior & 0,779 \\
Kinerja UMKM & 0,905 \\
\hline
\end{tabular}

Sumber: Output SmartPLS 3.2.8 data primer diolah 2019

Berdasarkan data pada table 9 diatas, dapat diketahui bahwa nilai Cronbach's Alpha dari masing-masing variabel penelitian $\geq 0,60$. Dengan demikian hasil ini dapat menunjukkan bahwa masing-masing variabel penelitian telah memenuhi persyaratan nilai Cronbach's Alpha, sehingga dapat dinyatakan bahwa variabel memiliki tingkat reliabilitas yang baik, dan dapat diterima. Selain mengamati Cronbach's Alpha, reliabilitas juga dapat diketahui melalui composite reliability untuk masing-masing indikator diisyaratkan nilainya harus $\geq 0,70$. untuk model yang baik.

Tabel 10 Composite Reliability

\begin{tabular}{lc}
\hline Variabel & Composite Reliability \\
\hline Komunikasi Interpersonal & 0,893 \\
Knowledge Sharing Behavior & 0,872 \\
Kinerja UMKM & 0,929 \\
\hline
\end{tabular}

Sumber: Output SmartPLS 3.2.8 data primer diolah 2019

Berdasarkan data pada tabel 10 diatas, dapat diketahui bahwa nilai Composite Reliability variabel penelitian $\geq 0,70$. hasil ini menunjukkan bahwa masing-masing variabel telah memenuhi Composite Reliability sehingga dapat dinyatakan bahwa variabel penelitian memiliki tingkat reliabilitas yang baik dan dapat diterima.

\section{Pengujian Inner Model (Model Struktural)}

Pengujian inner model dilakukan untuk melihat nilai signifikasi hubungan antara variabel laten dengan uji t sesuai parameter jalur strukturalnya dan nilai R-square dari model penelitian. Pengujian tersebut dilakukan melalui SmartPLS 3.2.8 dengan melakukan langkah calculate-boostrapping dan diperoleh hasil sebagai berikut: 
Tabel 11 R-Square

\begin{tabular}{ll}
\hline Variabel & R-Square \\
\hline Knowledge Sharing Behavior & 0,236 \\
Kinerja UMKM & 0,352 \\
\hline
\end{tabular}

Berdasarkan data pada tabel 11 diatas, dapat diketahui bahwa nilai S-quare untuk variabel Knowledge Sharing Behavior adalah 0,236 yang berarti variable Komunikasi Interpersonal mempengaruhi variabel Knowledge Sharing Behavior masuk dalam kategori (lemah). Sedangkan untuk variabel Kinerja UMKM nilai R-square sebesar 0,352 yang artinya variabel Komunikasi Interpesonal mempengaruhi variabel Kinerja UMKM melalui variabel Knowledge Sharing Behavior masuk dalam kategori kuat atau baik. Berdasarkan nilai $R$-square tersebut dapat dikatakan Kinerja UMKM dipengaruhi oleh variabel independen dan variabel intervening. sebesar 30\%, sedangkan sisanya 70\% dipengaruhi oleh variabel lain. Selanjutnya untuk menghitung nilai $Q$-square dapat dilakukan sebagai berikut.

Diketahui: $\quad R_{1}^{2}=0,236$

$$
Q^{2}=1-\left(1-R_{1}^{2}\right)\left(1-R_{2}^{2}\right) \ldots\left(1-R_{p}^{2}\right)
$$

Sehingga:

$$
R_{2}^{2}=0,352
$$

$$
\begin{aligned}
& Q^{2}=1-\left(1-R_{1}^{2}\right)\left(1-R_{2}^{2}\right) \\
& Q^{2}=1-(1-0,236)(1-0,352) \\
& Q^{2}=1-(0,764)(0,648) \\
& Q^{2}=1-(0,495) \\
& Q^{2}=0,505
\end{aligned}
$$

$Q$-square digunakan untuk mengukur seberapa baik nilai observasi yang dihasilkan model dan juga estimasi parameternya. Apabila $Q$-squre lebih dari 0 (nol), maka model layak dikatakan memiliki nilai prediktif yang relevan. Besarnya $Q^{2}$ memiliki nilai dengan rentang $0<Q^{2}<1$, dimana semakin mendekati 1 berarti model semakin baik. Berdasarkan perhitungan di atas nilai Prediction Relevance ( $Q$ Square) adalah 0,505 yang artinya memiliki kapasitas prediksi yang besar dan model yang baik.

Tabel 12 Path Coefficient

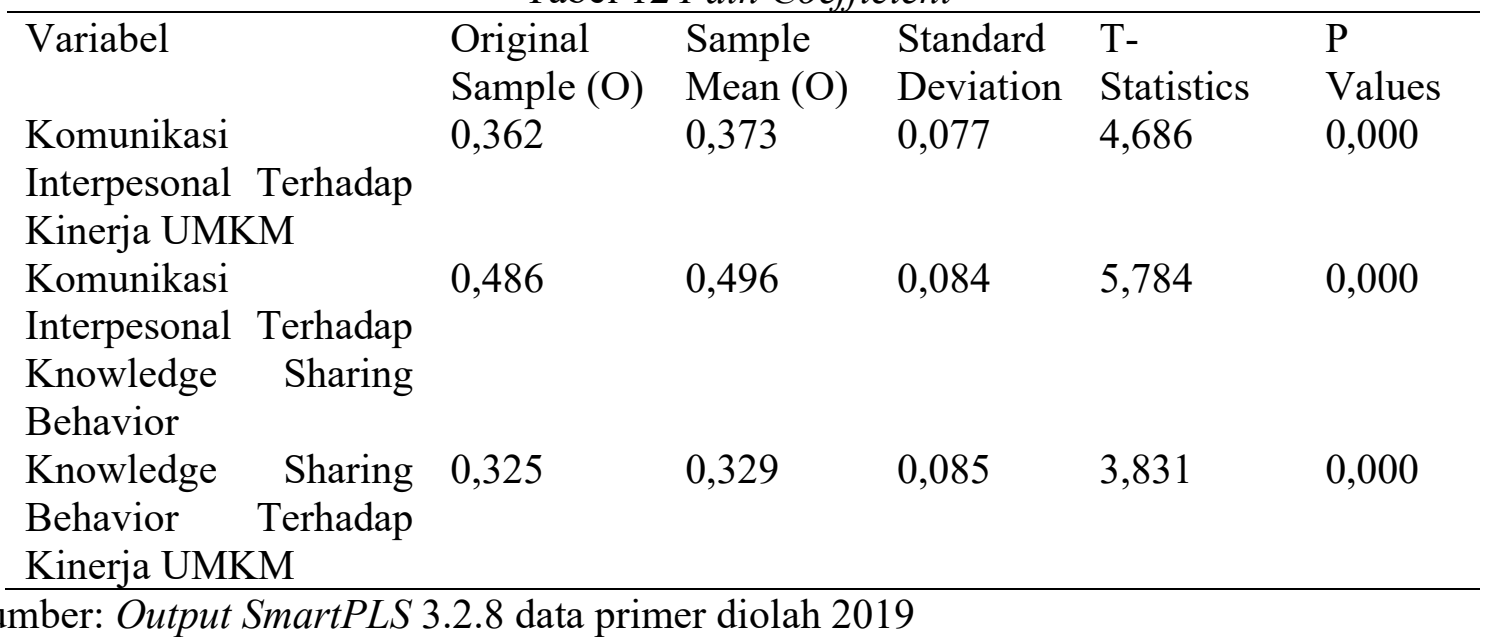


Tabel 13 Specific Indirect Effects

\begin{tabular}{llllll}
\hline & $\begin{array}{l}\text { Original } \\
\text { Sample } \\
(\mathrm{O})\end{array}$ & $\begin{array}{l}\text { Sample } \\
\text { Mean } \\
(\mathrm{O})\end{array}$ & $\begin{array}{l}\text { Standard } \\
\text { Deviation }\end{array}$ & $\begin{array}{l}\mathrm{T}- \\
\text { Statistics }\end{array}$ & Values \\
KI -> KSB ->KU & 0.158 & 0.163 & 0.051 & 3.117 & 0.002 \\
\hline
\end{tabular}

Sumber: Output SmartPLS 3.2.8 data primer diolah 2019

Tabel 14 Total Effects

\begin{tabular}{llllll}
\hline Variabel & $\begin{array}{l}\text { Original } \\
\text { Sample } \\
(\mathrm{O})\end{array}$ & $\begin{array}{l}\text { Sample } \\
\text { Mean } \\
(\mathrm{O})\end{array}$ & $\begin{array}{l}\text { Standard } \\
\text { Deviation }\end{array}$ & $\begin{array}{l}\mathrm{T}- \\
\text { Statistics }\end{array}$ & $\begin{array}{l}\text { P } \\
\text { Values }\end{array}$ \\
$\begin{array}{l}\text { Komunikasi } \\
\text { Interpesonal } \\
\text { Terhadap Kinerja }\end{array}$ & 0,520 & 0,536 & 0,072 & 7.256 & 0,000 \\
UMKM & & & & & \\
$\begin{array}{l}\text { Komunikasi } \\
\text { Interpesonal }\end{array}$ & 0,486 & 0,496 & 0,084 & 5,784 & 0,000 \\
$\begin{array}{l}\text { Terhadap } \\
\text { Knowledge }\end{array}$ & & & & & \\
$\begin{array}{l}\text { Sharing Behavior } \\
\text { Knowledge } \\
\text { Sharing Behavior }\end{array}$ & 0,325 & 0,329 & 0,085 & 3,831 & 0,000 \\
Terhadap Kinerja & & & & & \\
UMKM & & & & & \\
\hline
\end{tabular}

Sumber: Output SmartPLS 3.2.8 data primer diolah 2019

Hasil pengujian dapat dilihat dari table 12 di atas. original sample estimate Komunikasi Interpersonal Terhadap Kinerja UMKM adalah sebesar 0,362 dengan signifikansi 5\% yang di tunjukkan dengan nilai $t$-statistik 4,686 lebih besar dari nilai $t$-tabel sebesar 1,962 serta $p$ values 0,000 lebih kecil dari 0,05. Sedangkan nilai original sample estimate positif mengindentifikasikan bahwa Komunikasi interpersonal 0,362 berpengaruh positif terhadap Kinerja UMKM. Berdasarkan hasil tersebut dapat disimpulkan bahwa hipotesis H1 diterima. Hal ini sesuai dengan teori menurut Muhammad (2014) Komunikasi Interpersonal semakin baik dan efektif, maka kinerja UMKM juga semakin meningkat dan mendukung kuat bahwa ada hubungan kualitas dan kuantitas komunikasi dengan kinerja UMKM.Hal ini menunjukkan variabel komunikasi Interpersonal berpengaruh signifikan terhadap kinerja UMKM.

Hasil pengujian dapat dilihat dari Tabel 12, Komunikasi Interpesonal Terhadap Knowledge Sharing Behavior memperoleh nilai original sample estimate sebesar 0,486 dengan nilai t-statistik 5,784 $>1,962$ serta p-values $0,000<0,05$ yang berarti Komunikasi Interpersonal berpengaruh positif signifikan terhadap Knowledge Sharing Behavior dengan tingkat signifikansi 5\%. Berdasarkan hasil pengujian tersebut dapat disimpulkan bahwa hipotesis $\mathrm{H} 2$ diterima. Gaya komunikasi yang kuat dan berbeda terkait dengan pengetahuan berbagi perilaku, dirasakan kinerja pemimpin, kepuasan dengan pemimpin, dan komitmen tim bawahan. Multiple analisis regresi menunjukkan bahwa gaya kepemimpinan dimediasi hubungan antara gaya komunikasi dan hasil kepemimpinan. Namun, ketepatan pemimpin menjelaskan varians dalam kinerja pemimpin dirasakan dan kepuasan dengan pemimpin di atas dan di luar variabel gaya kepemimpinan.Reinout E.de Vries (2010). 
Hasil pengujian dapat dilihat dari Tabel 12, Knowledge Sharing Behavior Terhadap Kinerja UMKM memperoleh nilai original sample estimate sebesar 0,325 dengan nilai $t$ statistik 3,831 > 1,962 serta p-values 0,000 < 0,05 yang berarti Knowledge Sharing Behavior berpengaruh positif Terhadap Kinerja UMKM dengan tingkat signifikansi 5\%. Knowlegde sharing menciptakan peluang untuk memaksimalkan kemampuan organisasi untuk memenuhi kebutuhan tersebut dan menghasilkan solusi dan efisiensi yang menyediakan bisnis dengan keunggulan kompetitif Reid (2003). Knowlegde sharing dapat mendefinisikan sebagai budaya interaksi sosial, melibatkan pertukaran pengetahuan karyawan, pengalaman, dan keterampilan melalui seluruh Departemen atau organisasi Knowlegde sharing terdiri dari satu set pemahaman bersama yang berkaitan dengan memberikan karyawan akses ke informasi yang relevan dan membangun dan menggunakan jaringan pengetahuan dalam organisasi (Hogelet Al., 2003).

Hasil pengujian Pada tabel 13 dapat dilihat Specific Indirect Effects dari KI -> KSB $>\mathrm{KU}$, nilai original sample estimate sebesar 0.158 dan nilai t-statistik sebesar 3.117 di atas nilai t-tabel 1,962 serta $\mathrm{p}$-values $0,002<0,05$ yang berarti Komunikasi Interpersonal berpengaruh positif dan signifikan terhadap kinerja umkm melalui knowledge sharing dengan variabel intervening. Berdasarkan hasil pengujian tersebut dapat disimpulkan bahwa hipotesis H4 diterima. Hasil penelitian ini sejalan dengan penelitian yang dilakukan Agustin (2012) yang menyatakan bahwa knowledge sharing menjadi media untuk memfasilitasi karyawan dalam menyampaikan ide atau gagasan. Dengan karyawan menyampaikan ide atau gagasan maka akan terjadi komunikasi antara bawahan ke atasan maupun sesama rekan kerja dan terjadi hubungan timbal balik antar karyawan yang akan berbagi pengetahuan.

\section{SIMPULAN}

Penelitian ini memberikan bukti empiris mengenai Pengaruh Komunikasi Interpersonal Terhadap Kinerja UMKM Dengan Knowledge Sharing. Penelitian ini dilakukan di Pusat kuliner Tunggal Sangomang di Palangka Raya bahwa: Komunikasi Interpersonal berpengaruh positif signifikan Terhadap Kinerja UMKM di Kota Palangka Raya Komunikasi Interpesonal berpengaruh positif signifikan Terhadap Knowledge Sharing Behavior di Kota Palangka Raya. Knowledge Sharing Behavior berpengaruh positif signifikan Terhadap Kinerja UMKM di Kota Palangka Raya.Komunikasi Interpersonal terhadap Kinerja UMKM melalui Knowledge Sharing sebagai Variabel Intervening,.

Saran yang dapat diberikan berdasarkan hasil penelitian adalah: Penelitian selanjutnya diharapkan agar mendapatkan suatu model penelitian yang baik dengan didukung oleh teori yang kuat dan disarankan untuk lebih memperbanyak referensi penelitian yang mampu mendukung topik yang diteliti Penelitian selanjutnya diharapkan dapat melakukan pengujian model yang lebih dikembangkan, sehingga hasil penelitian dapat lebih memberi gambaran yang lebih baik terhadap UMKM.Penelitian selanjutnya diharapkan agar dapat melakukan penelitian pada subjek UMKM yang lebih besar.

\section{REFERENSI}

Arni,Muhammad, (2014) Pengaruh Komunikasi Organisasi Tehadap Knowledge Sharing dan kinerja karyawan. (Studi pada Karyawan Hotel Gajah Mada Graha Malang). Jurnal Administrasi Bisnis S1 Universitas Brawijaya, 35(2), 86-93.

Curado, C., \& Vieira, S. (2019). Trust, knowledge sharing and organizational commitment in SMEs. Personnel Review.

De Vries, R.E., Bakker-Pieper, A., \& Oostenveld,W.(2010). Leadership = Communication? The Relations of Leaders' Communication Styles with Leadership Styles, Knowledge 
Sharing and Leadership Outcomes. Journal of Business and Psychology 25(3):367-380 Hogel, M., Parboteeah, K.P. and Munson, C.L. (2003), "Team-level antecedents of individuals' knowledge networks", Decision Sciences, Vol. 34 No. 4, pp. 741-70.

Irdiani, Agustin. (2012). Peran Knowledge Sharing di Kalangan Karyawan (Studi Deskriptif pada PT. Perusahaan Listrik Negara (PERSERO) Distribusi Jawa Timur). Skripsi Program Studi Ilmu Informasi dan Perpustakaan. Universitas Airlangga.

Levin, D. Z., \& Cross, R. (2004). The strength of weak ties you can trust: The mediating role of trust in effective knowledge transfer. Management Science, 50(11), 1477-1490.

Reid, F. (2003), "Creating a knowledge sharing culture among diverse business units", Employment Relations Today, Vol. 30 No. 3, pp. 43-9.

Soegoto, E. S. (2018). Effective Enterprise Communication and Learning Attitude in Business Performance: A Case Study on SMEs. European Research Studies, 21(4), 55-68. 